\title{
New leafhopper species and new records of Typhlocybini (Hemiptera, Cicadellidae, Typhlocybinae) from China
}

\author{
Xian Zhou', Yalin Zhang', Min Huang' \\ I Key Laboratory of Plant Protection Resources and Pest Management of Ministry of Education, Entomological \\ Museum, College of Plant Protection, Northwest A\& F University, Yangling, Shaanxi Province, 712100, China \\ Corresponding authors: Yalin Zhang (yalinzh@nwsuaf.edu.cn), Min Huang (huangmin@nwsuaf.edu.cn)
}

Academic editor: Mick Webb | Received 28 August 2021 | Accepted 6 January 2022 | Published 20 January 2022

http://zoobank.org/8C1CFB38-1449-4FOB-8129-F3257AE75A2F

Citation: Zhou X, Zhang Y, Huang M (2022) New leafhopper species and new records of Typhlocybini (Hemiptera, Cicadellidae, Typhlocybinae) from China. ZooKeys 1082: 135-151. https://doi.org/10.3897/zookeys.1082.73611

\begin{abstract}
Five genera from China of the leafhopper tribe Typhlocybini are treated. Linnavuoriana Dlabola, 1958 and Shamala Dworakowska, 1980 and seven known species, Edwardsiana corylicola Vilbaste, 1968, E. praedestina Dlabola, 1967, E. singularis Anufriev, 1975, Hiratettix distanti Dworakowska, 1982, H. malaisei Dworakowska, 1982, L. antiqua Dworakowska, 1982, and L. malicola Zachvatkin, 1949 are newly recorded from China. Two new species, Shamala annulata and Paracyba biprocessa spp. nov., are described and illustrated. Keys to Chinese species of each genus are also provided.
\end{abstract}

\section{Keywords}

Auchenorrhyncha, distribution, morphology, taxonomy, Typhlocybini

\section{Introduction}

Typhlocybini (Hemiptera, Cicadellidae, Typhlocybinae) is a moderately large leafhopper tribe with over 924 species in 93 genera worldwide, of which 253 species in 44 genera have been recorded from China (including Zyginellini) (Dmitriev 2003; Yan 2019). Recent studies on Typhlocybinae from China have revealed many new taxa and new re- 
cords, especially in the tribe Typhlocybini. Here, we treat nine species belonging to five genera of this tribe, including two new species which are described and illustrated and seven new records. Updated keys to Chinese species of each genus are also provided.

\section{Materials and methods}

Figures of the specimens were made using a Leica M205 light microscope with a Leica DFC425 camera. Images were produced using the Leica Application Suite V3.7 and edited using Adobe Photoshop CS6.0 (Adobe Systems). Abdomens were removed from examined specimens and macerated in cold $10 \% \mathrm{NaOH}$ solution overnight, subsequently rinsed for $30 \mathrm{~s}$ with pure water, and stored in glycerin. An Olympus SZX10 microscope was used for dissecting specimens and an Olympus PM-10AD was used for drawing the dissected male genitalia.

Morphological terminology in this work follows Zhang (1990), but wing venation follows Dworakowska (1993).

Type specimens of the new species are deposited in the collections of the Entomological Museum, Northwest A\&F University, Yangling, China (NWAFU).

\section{Taxonomy}

\section{Edwardsiana Zachvatkin}

Edwardsiana Zachvatkin, 1929: 439.

Type species. Cicada rosae Linnaeus, 1758, by original designation.

Remarks. The genus Edwardsiana includes 80 known species worldwide (Dmitriev 2003), with two species having been reported from China. Here we record three more species from China and provide a key to all Chinese species.

Diagnosis. Body cream with variable patches (Figs 1-3). Crown bluntly produced, medial length shorter than distance between eyes; coronal suture distinct. Pronotum slightly wider than head (Figs 6-8). Forewing with apical area short, 1/4-1/3 of total length; RP and MP' petiolate or not. Hind wing with $\mathrm{R}$ and $\mathrm{M}$ confluent distally.

Male sternal abdominal apodemes well developed, often extending to middle of $6^{\text {th }}$ sternite.

Male genitalia. Pygofer side often with rounded extension at basal angle; ventral part always with depressed areas, dense stout setae on ventral-basal part and row of short rigid setae caudally. Subgenital plate elongate with subapical part twisted outwards; long macroseta basally and row of short rigid setae from middle to subapex. Paramere with distal part long and curved. Connective with central ridge developed. Aedeagus with preatrium and dorsal apodeme developed; aedeagal shaft with paired apical processes; gonopore apical.

Distribution. Palaearctic and Nearctic regions. 


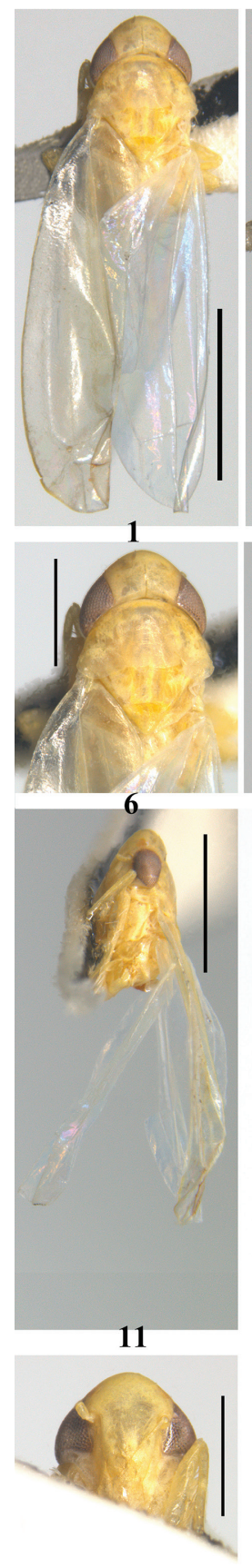

16
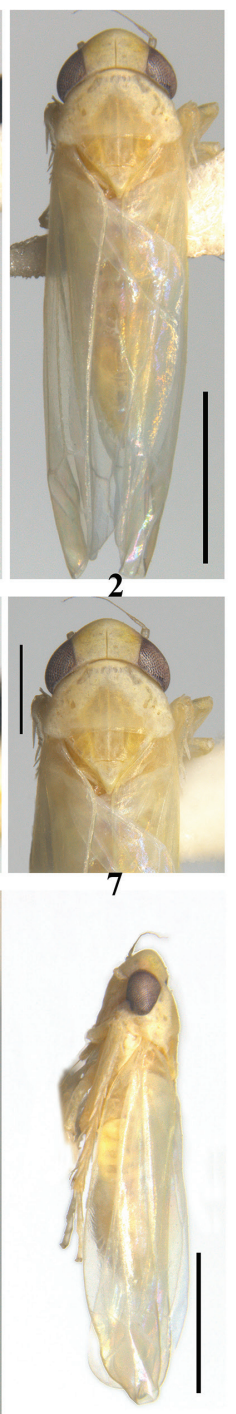

12

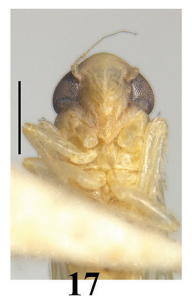

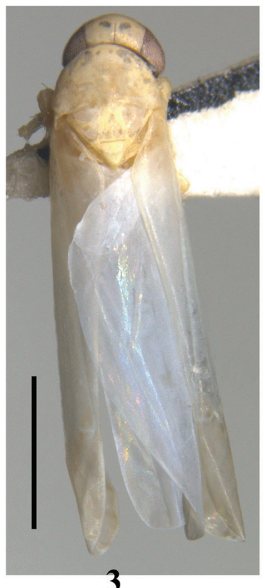
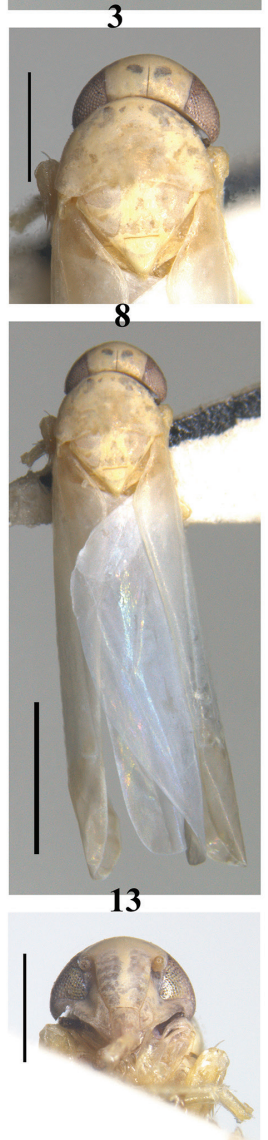

18
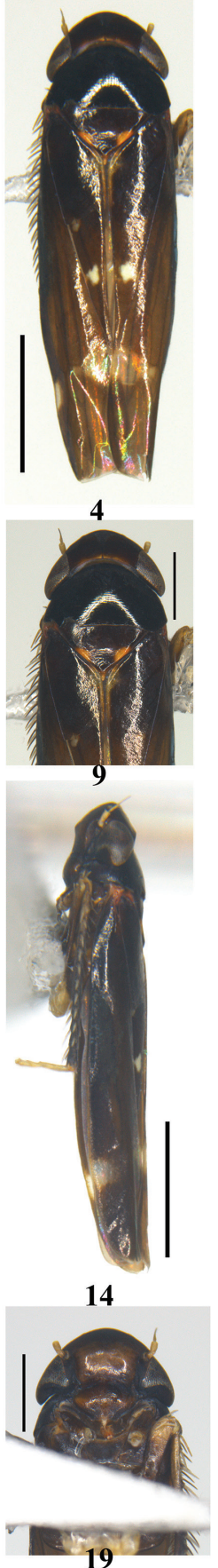
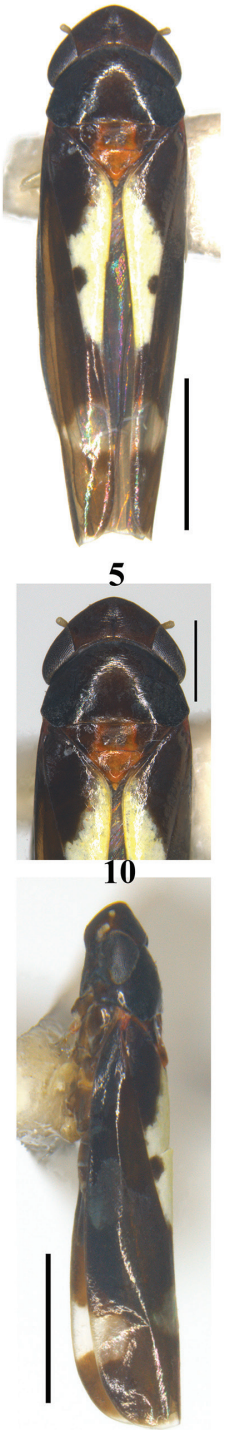

15

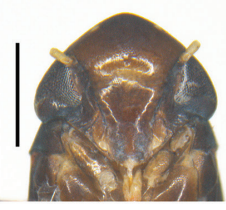

20

Figures I-20. Typhlocybini of China I-5 dorsal view 6-10 head and thorax, dorsal view I I-I $\mathbf{5}$ lateral view I 6-20 face I, 6, I I, $\mathbf{1} \mathbf{6}$ Edwardsiana corylicola 2, 7, I 2, $\mathbf{1 7}$ E. praedestina 3, 8, I 3, I 8 E. singularis 4, 9, 14, 19 Hiratettix distanti 5, 10, 15, $20 \mathrm{H}$. malaisei. Scale bars: $1.0 \mathrm{~mm}(\mathbf{I}-\mathbf{5}, \mathbf{I} \mathbf{I}-\mathbf{I}$ 5); $0.5 \mathrm{~mm}$ (6-10, 16-20). 
Key to species (males) of the genus Edwardsiana from China

1 Aedeagal shaft with two pairs of unbranched apical processes .E. rosae (Linnaeus)

- $\quad$ Aedeagal shaft with apical processes branched.............................................2

2 Aedeagal shaft with both dorsal and ventral processes branched (Figs 41, 42) E. singularis Anufriev

- $\quad$ Aedeagal shaft just with dorsal processes branched ...................................... 3

3 Ventral processes of aedeagal shaft short and directed ventrad (Figs 37, 38) .. E. corylicola Vilbaste

- Ventral processes of aedeagal shaft long and directed dorsad .......................4

4 Aedeagal shaft with dorsal and ventral processes branched near base (Figs 39, 40) ..E. praedestina Dlabola

- $\quad$ Aedeagal shaft with dorsal and ventral processes branched at middle or near apex

E. ishidai (Matsumura)

Edwardsiana corylicola Vilbaste, rec. nov.

Figs 1, 6, 11, 16, 37, 38

Edwardsiana corylicola Vilbaste, 1968: 98, Dworakowska 1982: 121, figs 205, 206.

Specimens examined. $2 \hat{\jmath} \widehat{\jmath}, 2 q+$, China, Heilongjiang Province, Mishan, 2.ix.2001, coll. Qiang Sun.

Distribution. China (Heilongjiang), Russia, Korea, North Korea.

\section{Edwardsiana ishidai (Matsumura)}

Typhlocyba ishidai Matsumura, 1932: 98, pl. II, fig. 3a, b.

Typhlocyba lanternae Wagner, 1937: 154.

Edwardsiana ussurica Vilbaste, 1968: 97.

Edwardsiana ishidai (Matsumura): Dworakowska 1982: 112, figs 156-178; Huang and Zhang 2002: 290.

Distribution. China (Jilin), Japan, Mongolia, Russia.

Edwardsiana praedestina Dlabola, rec. nov.

Figs 2, 7, 12, 17, 39, 40

Edwardsiana praedestina Dlabola, 1967: 217, figs 12-14. 

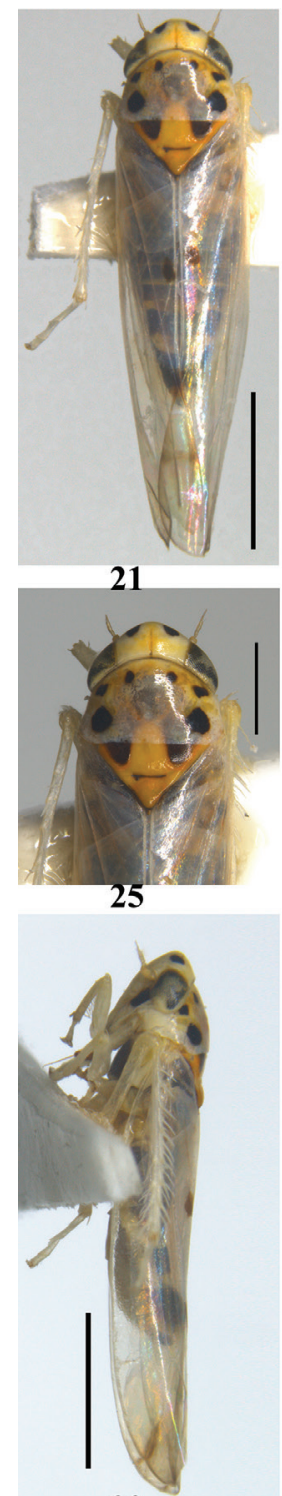

29

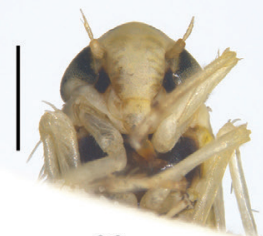

33

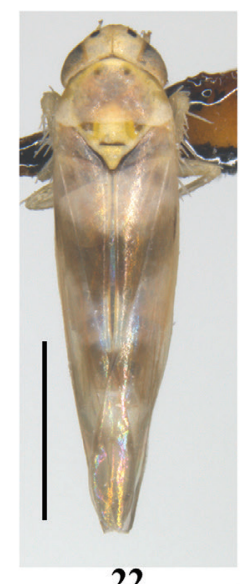

22

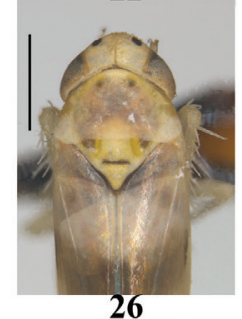

26

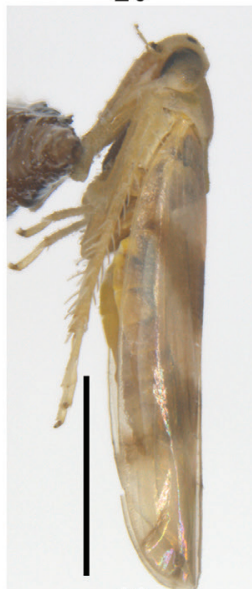

30

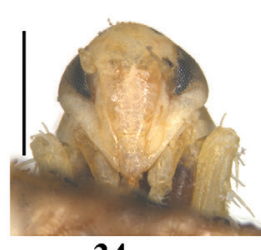

34

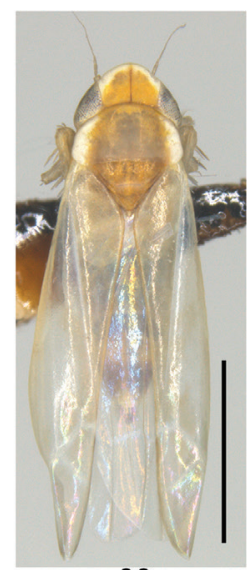

23

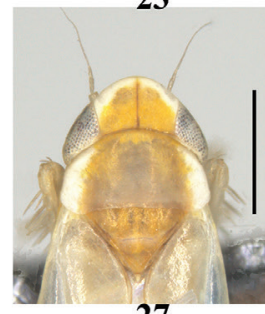

27

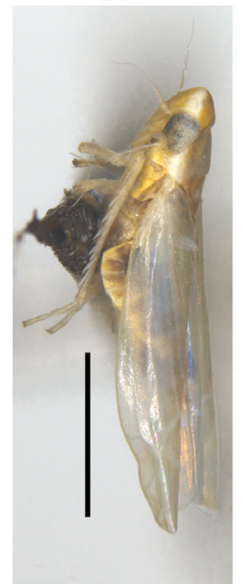

31

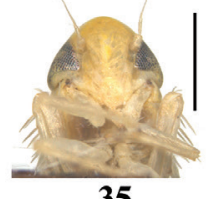

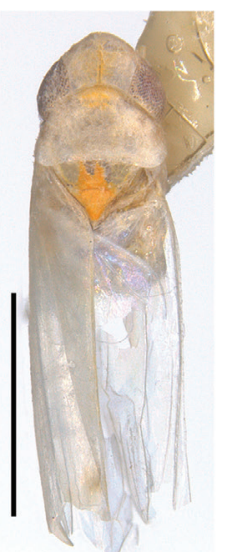

24
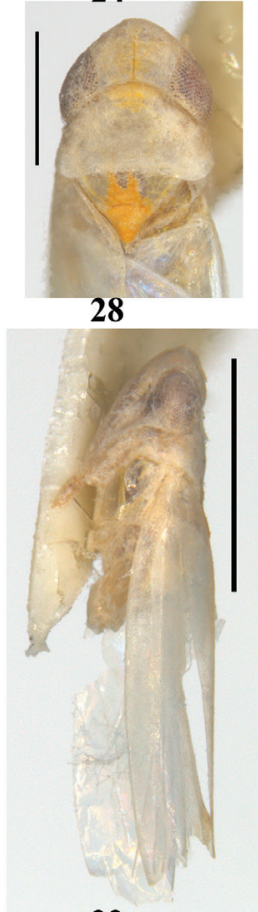

32

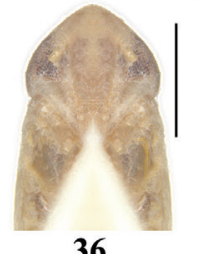

Figures 21-36. Typhlocybini of China 21-24 dorsal view 25-28 head and thorax, dorsal view 29-32 lateral view 33-36 face 21, 25, 29, 33 Linnavuoriana antiqua 22, 26, 30, 34 L. malicola 23, 27, 31, 35 Paracyba biprocessa sp. nov. 24, 28, 32, 36 Shamala annulata sp. nov. Scale bars: $1.0 \mathrm{~mm}$ (2I-24, 29-32); $0.5 \mathrm{~mm}(\mathbf{2 5 - 2 8 , 3 3 - 3 6 ) . ~}$ 
Specimens examined. $1 \delta^{\lambda}, 19 q \circ$, China, Shandong Province, Kunyu Mountain, 12.vii.2001, coll. Daozheng Qin and Zhenjiang Liu.

Distribution. China (Shandong), Mongolia.

\section{Edwardsiana rosae (Linnaeus)}

Cicada rosae Linnaeus, 1758: 439.

Edwardsiana subrosea Vilbaste, 1980: 41.

Edwardsiana rosae (Linnaeus): Dworakowska 1982: 107, figs 106-117.

Distribution. China (Gansu, Xinjiang), Cyprus, Turkey, Iran, Russia, Kazakhstan, Kirghizstan, Uzbekistan, Tajikistan.

\section{Edwardsiana singularis Anufriev, rec. nov.}

Figs 3, 8, 13, 18, 41, 42

Edwardsiana singularis Anufriev, 1975: 531; Dworakowska 1982: 117, figs 216, 217.

Specimens examined. $1 \curvearrowright$, China, Heilongjiang Province, Mishan, 2.ix.2001, coll. Qiang Sun.

Distribution. China (Heilongjiang), Russia, Kazakhstan.

\section{Hiratettix Matsumura}

Hiratettix Matsumura, 1931: 59 (in key); Matsumura 1932: 102 (full description); Dworakowska 1982: 152.

Type species. Hiratettix arisanellus Matsumura, 1932.

Remarks. After Matsumura (1931) described the genus Hiratettix (in a key to genera), Dworakowska (1982) added three new species from China (Taiwan), Myanmar, and India, and Sohi et al. (1990) published a new species from Nepal. Here we report two species new to China and provide a key to the Chinese species.

Diagnosis. Body flat and overall black (Figs 4, 5). Face wide and short (Figs 19, 20). Pronotum with minute transverse sculpture (Figs 9, 10). Forewing with $3^{\text {rd }}$ apical cell triangular. Hind wing truncated terminally with two cross veins; apical cells short.

Male genitalia. Genital capsule high and short. Pygofer with several short rigid setae terminally on inner surface and long macrosetae ventrobasally. Subgenital plate broad basally, slightly narrowed distally, with several long macrosetae near middle part, a row of short rigid setae laterally and progressively shorter subbasally to apex. Connective wide with central lobe underdeveloped. Paramere thick with central part longer 


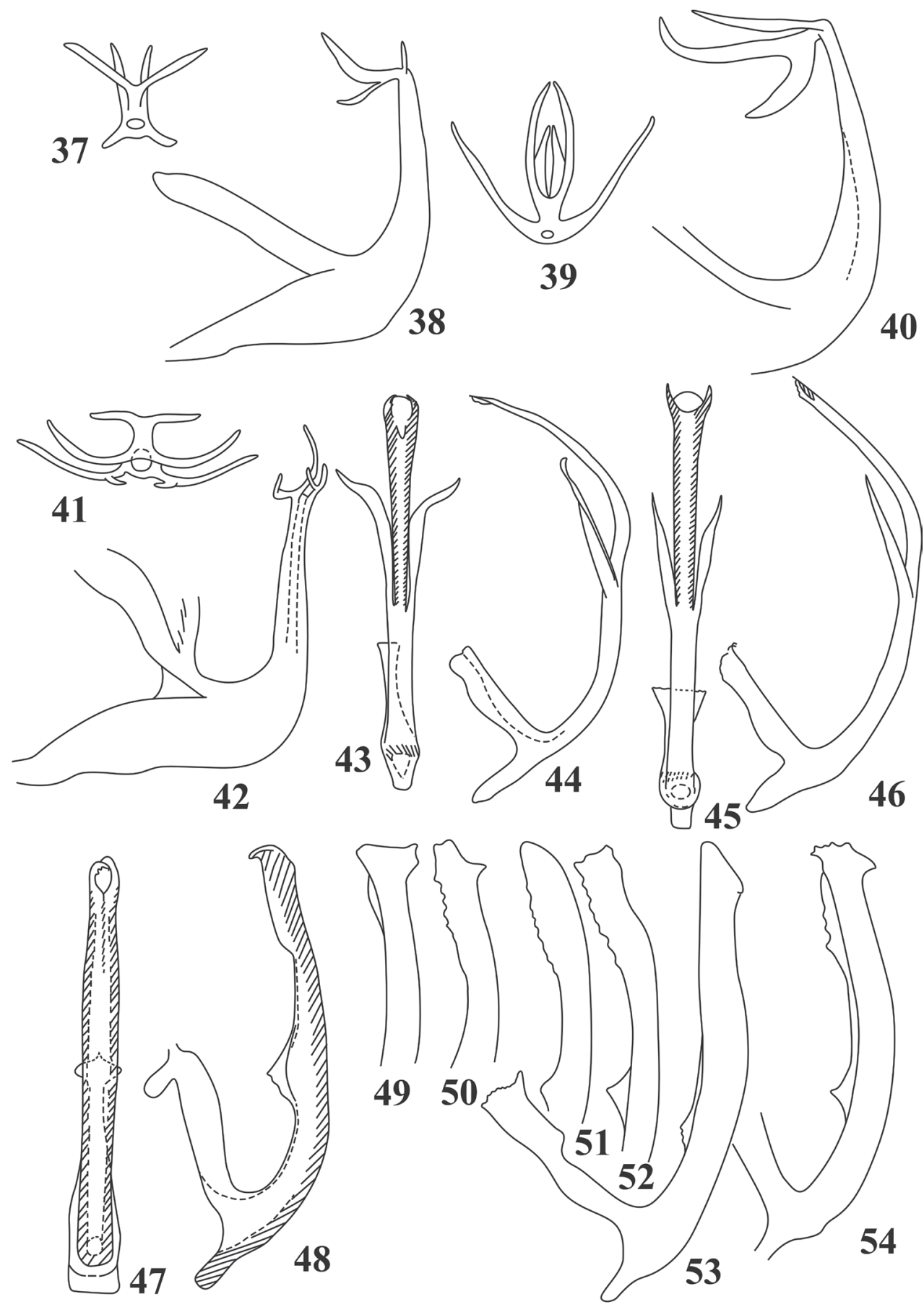

Figures 37-54. Male genitalia of Typhlocybini of China (after Dworakowska 1982) 37, 38 Edwardsiana corylicola 39, 40 E. praedestina 4I, 42 E. singularis 43, 44 Hiratettix distanti 45, 46 H. malaisei 47, 48 Linnavuoriana antiqua 49-54 L. malicola. 
than basal and distal parts together; caudal part with sensorial pits on inner margin. Aedeagal shaft with paired apical and lateral processes; gonopore apical.

Distribution. Oriental Region.

Key to species (males) of the genus Hiratettix from China

1 Aedeagal shaft with two long basal processes and two pairs of short apical processes ................................................................................................ 2

- $\quad$ Aedeagal shaft with two medium sized lateral processes and one pair of short apical processes .......................................................................................... 3

2 Aedeagal shaft with basal processes S-bent and two pairs of apical processes basally closed .................................................... H. arisanellus Matsumura

- $\quad$ Aedeagal shaft with basal processes arched and two pairs of apical processes detached from each other basally ................ H. matsumurai Dworakowska

3 Aedeagal shaft with median processes curved outwards, apical processes directed to each other distally (Figs 43,44$)$............. H. distanti Dworakowska

- $\quad$ Aedeagal shaft with median processes straight, apical processes widely separated distally (Figs 45, 46)

H. malaisei Dworakowska

\section{Hiratettix arisanellus Matsumura}

Hiratettix arisanellus Matsumura, 1932: 102; Dworakowska 1982:153, figs 635-649.

Distribution. China (Taiwan).

Hiratettix distanti Dworakowska, rec. nov.

Figs 4, 9, 14, 19, 43, 44

Hiratettix distanti Dworakowska, 1982: 154, figs 661-666.

Specimens examined. $1 \hat{\jmath}$, China, Yunnan Province, Mengla, Nangong Mountain, 1850 m, 13.xii.1999, coll. Dworakowska.

Distribution. China (Yunnan), India.

Hiratettix malaisei Dworakowska, rec. nov.

Figs 5, 10, 15, 20, 45, 46

Hiratettix malaisei Dworakowska, 1982: 153, figs 667-676.

Specimens examined. 1 $\delta^{\lambda}$, China, Sichuan Province, Emei Mountain, $950 \mathrm{~m}$, 30.x.1999, coll. Dworakowska. 1ô, 2 우, China, Guizhou Province, Huaxi, Huaxi 
Garden, 1100 m, 25.vii.2001, coll. Qiang Sun, at light. 1§, 14q , China, Yunnan Province, Shilin, 9.vii.2021, coll. Xian Zhou.

Distribution. China (Sichuan, Guizhou, Yunnan), Myanmar.

\section{Hiratettix matsumurai Dworakowska}

Hiratettix matsumurai Dworakowska, 1982: 153, figs 650-660.

Distribution. China (Taiwan).

\section{Linnavuoriana Dlabola, rec. nov.}

Linnavuoriana Dlabola 1958: 54; Dworakowska 1971: 647; Dworakowska 1982: 121.

Type species. Cicada decempunctata Fallen, 1806.

Remarks. Up to now, there are eight known species in the genus Linnavuoriana. In Xinjiang and Yunnan provinces, we collected two known species that are the first records of the genus from China. A key to the Chinese species is given.

Diagnosis. Body cream, light yellow (Figs 21, 22). Crown and pronotum with symmetrical black round patches, and basal triangle black (Figs 25, 26). Forewing semitransparent with light smoky brown or brown patches (Figs 21, 22, 29, 30).

Head bluntly produced, little narrower than width of pronotum, and $1 / 3$ times middle length of pronotum (Figs 25, 26). Forewing slender and obtuse apically with both sides parallel; RP+MP' petiolate at base; $1^{\text {st }}$ apical cell usually smallest; $2^{\text {nd }}$ apical cell biggest. Hind wing with two cross veins far away from each other.

Abdominal apodemes well developed, often extending to $5^{\text {th }}$ abdominal sternite.

Male genitalia. Hind margin of pygofer with inner ridge, several rigid microsetae near posterior-dorsal margin and numerous minute tubercles posteroventrally. Subgenital plate parallel-sided and lack macrosetae at base, narrowing from apical 1/3-1/2 of outer margin, rounded terminally, usually with row of rigid microsetae and some fine microsetae scattered on apex. Paramere rarely curved with subapical tooth; distally with row of microsetae on outer margin and row of sensorial pits on inner margin. Connective small with central ridge underdeveloped. Aedeagal shaft with a pair of triangular protrusions on dorsal surface laterally; gonopore apical.

Distribution. Oriental and Palaearctic regions.

\section{Key to species of Linnavuoriana from China (males)}

$1 \quad$ Crown and pronotum with large dark patches; aedeagal shaft with apex hooklike (Figs 47, 48) L. antiqua Dworakowska

- $\quad$ Crown and pronotum with few light patches; aedeagal shaft with apex not hook-like (Figs 49-54).

L. malicola (Zachvatkin) 
Linnavuoriana antiqua Dworakowska, rec. nov.

Figs 21, 25, 29, 33, 47, 48

Linnavuoriana antiqua Dworakowska, 1982: 123, figs 326-341.

Specimens examined. $1 \hat{\jmath}, 1 \uparrow$, China, Yunnan Province, Lijiang, Xinzhu Botanical Garden, 16.xi.1999, coll. Dworakowska. 1ð̄, Yunnan Province, Tengchong, 1650 m, 26.iv.1981, coll. Fasheng Li.

Distribution. China (Yunnan), India.

Linnavuoriana malicola (Zachvatkin), rec. nov.

Figs 22, 26, 30, 34, 49-54

Typhlocyba malicola Zachvatkin, 1949: 220.

Linnavuoriana taschkentica Dlabola, 1961: 302, figs 152-156. Synonymized by Mitjaev 1967: 710.

Linnavuoriana apunctata Mitjaev, 1963: 49, nec Dlabola.

Typhlocyba roseipennis Kusnezov, 1932: 232, nec Oshanin (Zachvatkin 1949;

Mitjaev 1967).

Linnavuoriana populicola Dubovsky, 1966: 132; Synonymized by Dworakowska 1982:

123, figs 313-325.

Specimens examined. $4 \widehat{\jmath}, 3 q+$, China, Xinjiang Province, Xinjiang Agricultural

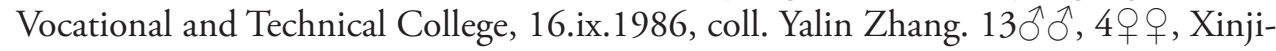
ang Agricultural University, 16.ix.1986, coll. Yalin Zhang.

Distribution. China (Xinjiang), Kazakhstan, Kirghizstan, Uzbekistan, Tajikistan, Afghanistan.

\section{Paracyba Vilbaste}

Paracyba Vilbaste, 1968: 96; Dworakowska 1982: 148, figs 602-621.

Type species. Zygina akashiensis Takahashi, 1928.

Remarks. Until now, thegenus Paracybaincluded threeknown species, including two speciesfrom China. Herewe add a new species from China and give a key to all species of the genus.

Diagnosis. Body slim. Head bluntly produced, middle length equal to or shorter than width between eyes, coronal suture long and distinct. Forewing laterally with apex rounded; RP and MP' petiolate at base; $1^{\text {st }}$ apical cell nearly equal in size to $4^{\text {th }}$ apical cell; $2^{\text {nd }}$ apical cell biggest. Hind wing with two cross veins.

Male sternal abdominal apodemes extending to distal margin of $4^{\text {th }}$ sternite.

Male genitalia. Pygofer side tall and divided into two or three small lobes caudally, upper lobe and central lobe with short rigid setae terminally, lower lobe deeply con- 
tracted, usually with long macrosetae. Subgenital plate elongate, triangular with a row of short fine setae subbasally to apex, with indistinct peg-like setae at apex. Paramere with basal part slim and central part broad, thereafter gradually tapered to apex, with a row of microsetae on outer margin. Connective trapezoidal. Aedeagus with short preatrium; dorsal apodeme well developed bifurcate apically; aedeagal shaft usually short with long and asymmetrical processes apically; gonopore apical.

Distribution. Oriental and Palaearctic regions.

\section{Key to species (males) of the genus Paracyba}

1 Aedeagal shaft with two distal processes (Figs 60-62)

P. biprocessa sp. nov.

- Aedeagal shaft with three distal processes ..................................................2

2 Aedeagus with lateral process arising from mid-length of shaft; two other processes slightly arched, longest process bent to right

P. akashiensis (Takahashi)

- $\quad$ Aedeagus with lateral process arising near apex; other two processes relatively straight, longest process bent to left ................................................................ 3

3 Two apical processes of aedeagus twice as long as subapical process

P. soosi Dworakowska

- $\quad$ Two apical processes of aedeagus nearly equal in length to subapical process. P. nopporensis Matsumura

\section{Paracyba akashiensis (Takahashi)}

Zygina akashiensis Takahashi, 1928: 442; Dworakowska 1982: 148, figs 602-614.

Distribution. China (Taiwan), Japan, Russia.

\section{Paracyba soosi Dworakowska}

Paracyba soosi Dworakowska, 1977: 41, figs 253-259.

Distribution. China (Hunan), Vietnam.

\section{Paracyba nopporensis (Matsumura)}

Typhlocyba nopporensis Matsumura, 1932: 100; Dworakowska 1982: 150, figs 615621.

Distribution. Japan, Russia. 


\section{Paracyba biprocessa sp. nov.}

http://zoobank.org/NomenclaturalActs/7504C225-8537-4115-91969783F7F4A8D4

Figs 23, 27, 31, 35, 55-62

Note. Head with coronal suture extended to anterior margin (Fig. 23). Face yellow, eyes dark brown, thorax light brown (Figs 27, 35). Crown with anterior margin white; pronotum with lateral margin white, remainder covered with a continuous large ocher patch extending to distal end of clavus of forewing (Figs 23, 27); scutellum with apex orange (Fig. 27). Forewing light ocher with few light smoky patches in apical half, remaining part transparent except for white brochosome field.

Male sternal abdominal apodemes extending to middle of $5^{\text {th }}$ sternite (Fig. 55).

Pygofer side tall and bilobate caudally, upper lobe with short setae terminally, lower lobe with several fine moderately long setae (Fig. 56). Subgenital plate elongate, triangular with single macroseta near base, a row of short rigid setae adjacent row of fine setae laterally and two indistinct peg-like setae apically (Fig. 58). Paramere with row of microsetae on outer margin and row of sensorial pits on inner margin (Fig. 59). Connective trapezoidal, with central ridge (Fig. 57). Aedeagal shaft with two apical processes, in ventral view left process slim, $\mathrm{S}$-shaped, right process short and straight (Figs 60-62).

Specimens examined. Holotype: ${ }^{\lambda}$, China, Shaanxi Province, Yangling, ix.1983,

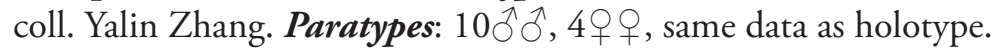

Measurement. Male, 3.1-3.3 mm (including wing).

Etymology. This new species is named for the two aedeagal processes, rather than three in other species.

Remarks. This new species resembles Paracyba soosi Dworakowska, 1977 in coloration and male genitalia, but it differs from the latter in aedeagal shaft having two rather than three distal processes and processes of very different length.

\section{Shamala Dworakowska, rec. nov.}

Shamala Dworakowska, 1980: 169, figs 174-187.

Type species. Shamala mikra Dworakowska, 1980.

Remarks. The genus Shamala was erected by Dworakowska (1980); thereafter she described four additional species from India and Nepal (1981), Sikkim (1994), and India (1982). In this paper, a new species, S. annulata sp. nov., from Yunnan, China, is described and illustrated which increases the number of valid species in this genus to six.

Diagnosis. Body slim and cream with occasional light brown patches. Head slightly wider than pronotum with length along midline slightly shorter than distance between eyes. Forewing parallel-sided, rounded terminally; RP and MP' petiolate at base. Hind wing gradually narrowing from base to apex and rounded terminally with two cross veins. 

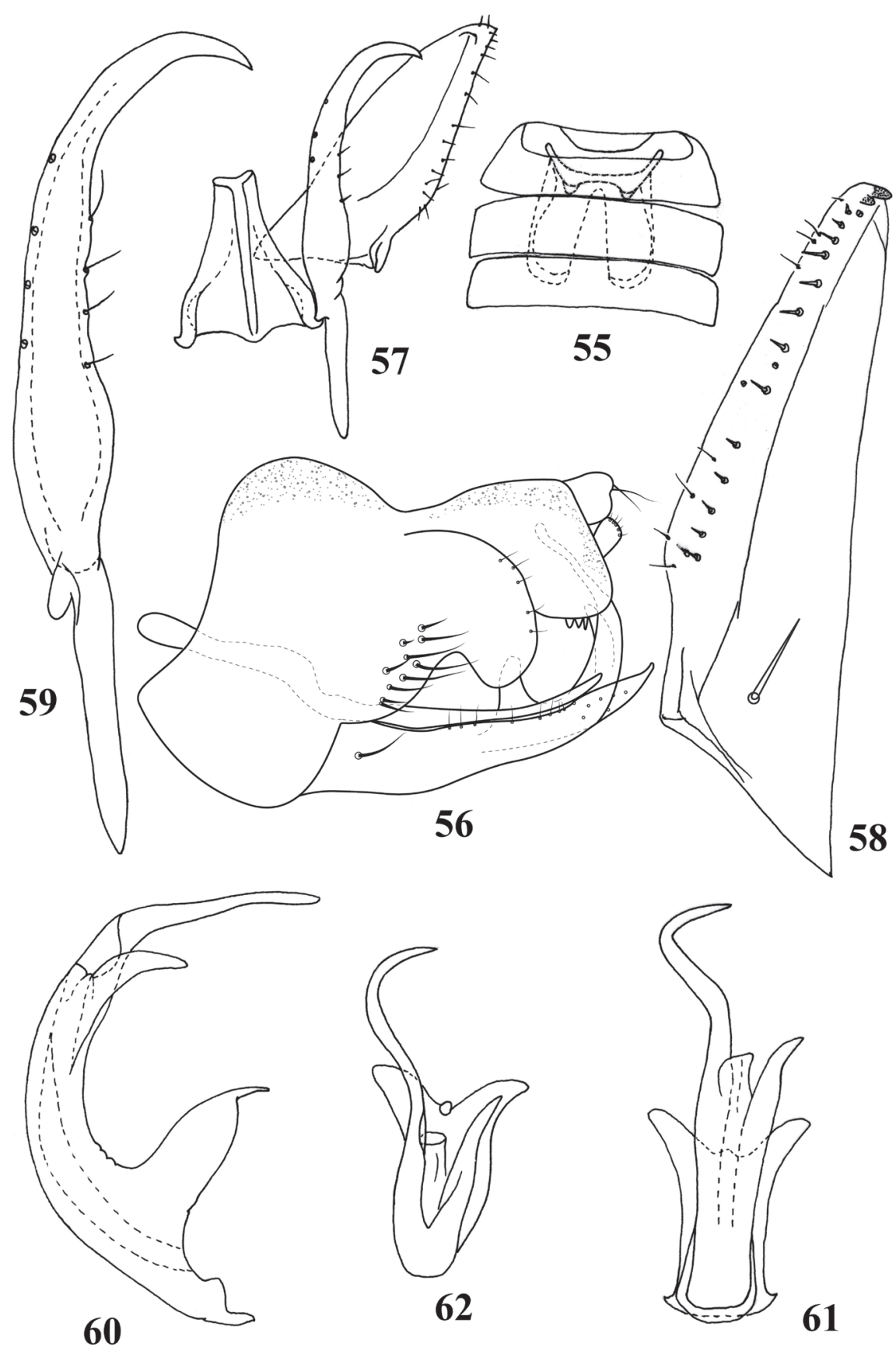

Figures 55-62. Male genitalia and sternal abdominal apodemes of Paracyba biprocessa sp. nov. 55 sternal abdominal apodemes $\mathbf{5 6}$ genitalia capsule, lateral view $\mathbf{5 7}$ paramere, connective and subgenital plate, dorsal view $\mathbf{5 8}$ subgenital plate $\mathbf{5 9}$ paramere $\mathbf{6 0}$ aedeagus, lateral view $\mathbf{6 I}$ aedeagus, posterior view $\mathbf{6 2}$ apical part of aedeagus, dorsal view. 
Male sternal abdominal apodemes extending to $4^{\text {th }}$ or $5^{\text {th }}$ sternite.

Male genitalia. Genital capsule short; pygofer side with a weekly sclerotized area near middle of hind margin; several rigid setae at caudo-ventral angle and macrosetae on middle part. Subgenital plate gradually narrowing towards apex with a macroseta at base and row of short peg-like setae from middle to apex of outer margin; two rigid setae apically and few fine setae on inner margin subapically. Connective laminate, with stem well developed. Paramere with caudad part long, with several setae on outer margin. Aedeagal shaft with distal asymmetrical processes; with long membranous terminal part.

Distribution. Oriental Region.

\section{Shamala annulata sp. nov.}

http://zoobank.org/3853DE59-4325-4DFB-A39B-F3364B8B0CC4

Figs 24, 28, 32, 36, 63-71

Note. Body cream (Fig. 24). Scutellum orange with basal triangles yellowish green (Fig. 28). Forewing bluish white with brownish patch on CuA".

Abdominal apodemes extending to distal margin of $4^{\text {th }}$ sternite.

Male genitalia. Pygofer side with several macrosetae ventrally and rigid short setae terminally (Figs 63, 64). Subgenital plate long and narrow with row of short peg-like setae from middle part to apex on outer margin (Fig. 66). Connective slender with short central lobe, stem relatively long (Fig. 68). Aedeagal shaft with four asymmetrical processes apically, of which two dorsal processes are longer and curved inward forming a ring-like shape, two ventral processes straight and slightly divergent (Figs 69-71).

Specimens examined. Holotype: $\hat{\jmath}$, China, Yunnan Province, Sanchahe, 7.vi.1991, coll. Rungang Tian. Paratypes: $3{ }^{\lambda} \partial^{\lambda}$, same data as holotype.

Measurement. Male, $2.94 \mathrm{~mm}$ (including wing).

Etymology. The name of this species is derived from the Latin word "annulus", referring to the two dorsal processes of the aedeagal shaft forming a ring-like shape.

Remarks. This new species resembles Shamala ricasta Dworakowska, 1981 in the structure of the male genitalia, but it differs from the latter by the two longer apical processes of aedeagal shaft forming a ring-like shape.

\section{Acknowledgements}

We are very grateful to Dr I. Dworakowska for her contribution to the knowledge of Chinese Typhlocybinae. We give sincere thanks to students in the Entomological Museum of Northwest A\&F University for their great help in obtaining specimens. We also thank Prof. John Richard Schrock (Emporia State University, USA) for proofreading of the manuscript and giving us valuable advice before submission. We extend our heartfelt gratitude to Mick Webb and Valérie Lemaittre (The Natural History Museum, 

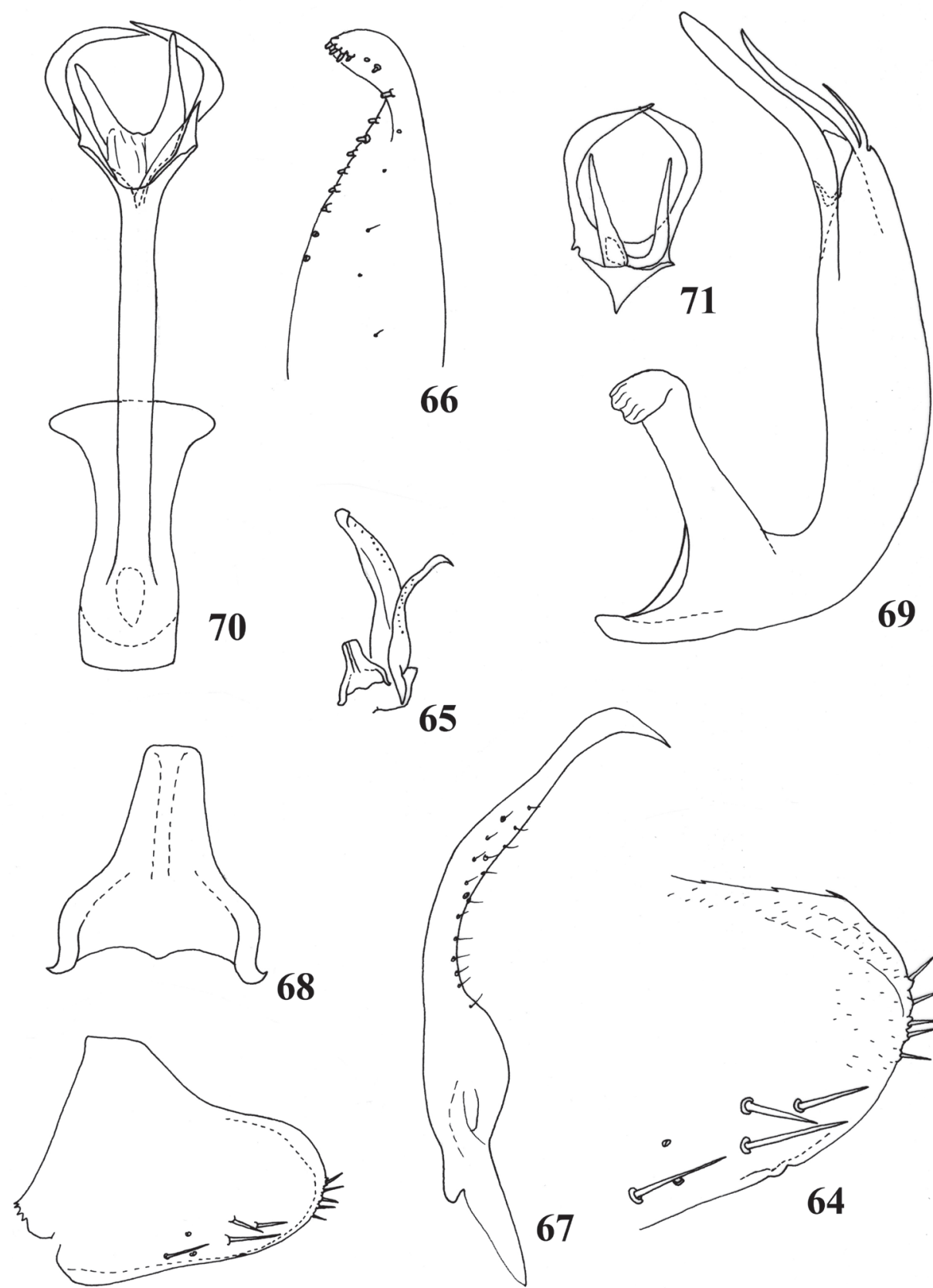

63

Figures 63-7I. Male genitalia of Shamala annulata sp. nov. 63, 64 pygofer side, lateral view 65 paramere, connective and subgenital plate, dorsal view $\mathbf{6 6}$ subgenital plate $\mathbf{6 7}$ paramere $\mathbf{6 8}$ connective $\mathbf{6 9}$ aedeagus, lateral view $\mathbf{7 0}$ aedeagus, posterior view $\mathbf{7 I}$ apical part of aedeagus, ventral view. 
London, UK) and anonymous reviewers for their earnest reviews. This study is supported by the National Natural Science Foundation of China (32070478, 31372233, 31420103911 ) and The Ministry of Science and Technology of the People's Republic of China (2006FY120100, 2015FY210300).

\section{References}

Anufriev GA (1975) Notes on the genus Edwardsiana Zachv. and Pithyotettix Rib. (Homoptera: Cicadellidae) with descriptions of two new species. Bulletin de l'Academie Polanaise des Sciences (Série des Sciences Biologiques) 23: 531-536.

Dlabola J (1958) A reclassification of Palaearctic Typhlocybinae (Homopt., Auchenorrh). Časopis Československé Společnosti Entomologické 55: 44-57.

Dlabola J (1961) Die Zikaden von Zentralasien, Dagestan und Transkaukasien (Homopt. Auchenorrhyncha). Acta Entomologica Musei Nationalis Pragae 34: 241-358.

Dlabola J (1967) Ergebnisse der 2. Mongolisch-tschechoslowakischen entomologisch-botanischen Expedition in der Mongolei. Nr. 12: Reisebericht, Lokalitateniibersicht und Bearbeitung der gesammelten Zikaden (Homopt., Auchenorrh.). Acta Faunistica Entomologica Musei Nationalis Pragae 12: 207-230.

Dmitriev DA (2003) 3i interactive keys and taxonomic databases. http://dmitriev.speciesfile. org/ [Accessed on: 2022-1-7]

Dubovsky GK (1966) Cicadina (Auchenorrhyncha) of the Fergana Valley. Uzbekistan SSR, Tashkent, 256 pp. [In Russian]

Dworakowska I (1971) Opamata gen. n. from Viet-Nam and some other Typhlocybini (Auchenorrhyncha, Cicadellidae, Typhlocybinae). Bulletin de l'Academie Polonaise des Sciences (Série des Sciences Biologiques) 19: 647-657.

Dworakowska I (1977) On some Typhlocybinae from Vietnam (Homoptera: Cicadellidae). Folia Entomologica Hungarica 30: 9-47.

Dworakowska I (1980) On some Typhlocybinae from India (Homoptera, Auchenorrhyncha, Cicadellidae). Entomologische Abhandlungen und Berichte aus dem Staatlichen Museum fur Tierkunde in Dresden 43: 151-201.

Dworakowska I (1981) On some Typhlocybini from India and Nepal (Auchenorrhyncha, Cicadellidae, Typhlocybinae). Bulletin de l'Academie Polonaise des Sciences (Série des Sciences Biologiques) 28: 593-602.

Dworakowska I (1982) Typhlocybini of Asia (Homoptera, Auchenorrhyncha, Cicadellidae). Entomologische Abhandlungen und Berichte aus dem Staatlichen Museum fur Tierkunde in Dresden 45: 99-181.

Dworakowska I (1993) Remarks on Alebra Fieb. and Eastern Hemisphere Alebrini (Auchenorrhyncha: Cicadellidae: Typhlocybinae). Entomotaxonomia 15(2): 91-121.

Huang M, Zhang YL (2002) A taxonomic study of the genus Thampoa Mahmood from China (Homoptera: Cicadellidae: Typhlocybinae). Entomotaxonomia 27: 290-303.

Kusnezov V (1932) Spisok: vrediteli selskogo hozjnjstva, podotrjad cikadovye. In: Vrednye nasekomye SSSR i sopredel'nyh stran, I. Trudy po Zashchite Rastenii Ser. I, Entomologiia. 
Linnaeus C (1758) II. Hemiptera. Systema Naturae: per regna tria naturae, secundum classes, ordines, genera, species cum characteribus, differentiis, synonymis, locis. Editio decima, reformata. L. Salvii, Stockholmiae, 1: 1-824. https://doi.org/10.5962/bhl.title.542

Matsumura S (1931) A revision of the Palaearctic and Oriental typhlocybid genera with descriptions of new species and new genera. Insecta Matsumurana 6: 55-91.

Matsumura S (1932) A revision of the Palaearctic and Oriental typhlocybid genera with descriptions of new species and new genera. Insecta Matsumurana 6: 93-120.

Mitjaev ID (1963) Data on the fauna and biology of Typhlocybinae (Homoptera; Auchenorrhyncha) of Kazakhstan. Trudy Instituta Zoologii Akademii Nauk Kazakhskoi SSR 21: 49-73. [In Russian]

Mitjaev ID (1967) On systematics and ecology of cicades [sic!] of the genus Linnavuoriana Dlab., 1958 (Homoptera, Typhlocybinae) of south-eastern Kazakhstan. Zoologicheskii Zhurnal 46: 710-714. [In Russian]

Sohi AS, Mann JS, Thapa VK (1990) A new species of Hiratettix Matsumura (Cicadellidae: Typhlocybinae) from Nepal. Journal of Insect Science 3: 115-117.

Takahashi S (1928) Treatise on Vegetable Insects. Sosai Gaichu Kakuron, 442 pp.

Vilbaste J (1968) Über die Zikadenfauna des Primorje Gebietes. Valgus, Tallinn, 178 pp. [In Russian]

Vilbaste J (1980) Homoptera Cicadinea of Tuva. Valgus, Tallinn, 217 pp. [In Russian]

Wagner W (1937) Am licht gefangene Typhlocybiden. Verhandlungen des Vereins für Naturwissenschaftliche Heimatforschung zu Hamburg 26: 154-155.

Yan B (2019) Study on Taxonomy and Molecular Systematics of Typhlocybini from China (Hemiptera: Cicadellidae: Typhlocybinae). Guizhou University, Guiyang, Guizhou, 1-3. [in Chinese]

Zachvatkin AA (1929) Description d'une nouvelle espèce du genre Edwardsiana Jaz. 1929 (Homoptera, Eupterygidae) des environs de Moscou. Revue Russe d'Entomologie 23: 262-265.

Zachvatkin AA (1949) II Vrediteli plodovo-jagodnyh kultur. Podotrjad (Cicadoidea) cikadovye. In: Vrednye zivotnye Srednej Azii. Moskva/Leningrad, 220-222.

Zhang YL (1990) A Taxonomic Study of Chinese Cicadellidae (Homoptera). Tianze Eldonejo, Yangling, Shaanxi, 218 pp. [in Chinese] 